\title{
Creación de una filmoteca de prácticas para la Facultad de Ciencias de la Información de la UCM: adecuación de espacio y estrategias de catalogación
}

\author{
Patricia GOROSKIETA ESTELLA \\ patriciagoroskieta@gmail.com \\ Clara SÁNCHEZ-DEHESA GALÁN \\ csdehesa@gmail.com
}

Recibido: 10/09/2015

Aceptado: 21/10/2015

\section{RESUMEN}

En el presente trabajo se da el primer paso para la creación de una Filmoteca de Prácticas en la facultad de Ciencias de la Información de la Universidad Complutense de Madrid. El Patrimonio Fílmico se ve gravemente expuesto al paso del tiempo y el abandono por lo que se necesita un rescate urgente. Mediante un riguroso trabajo de investigación, en el que se estudian diferentes propuestas y normativas expuestas por organismos especializados, se redacta un manual de inicio. Se han investigado, diseñado y propuesto las herramientas básicas y útiles para poner en funcionamiento la primera Filmoteca de Prácticas en el ámbito universitario español.

palabras clave: Material fílmico, archivo fílmico, preservación cinematográfica, normas de catalogación, patrimonio fílmico, conservación de material fílmico.

Creating a Practices Film Archive in the UCM: Adaptation of Space and Cataloging Strategies

\begin{abstract}
This work presents a first step to the setting-up of a Practices Film Archive in the Complutense University of Madrid. Film Heritage is gravely exposed to aging and abandonment and therefore needs urgent rescue. We report here a guide obtained from a comprehensive study of guidelines proposed by different specialized organizations. We have performed research, design and propose basic tools to put in place the first Practices Film Archive at University level.

Keywords: Film material, film archive, film preservation, cataloging norms, Film heritage, film conservation.

\section{Referencia normalizada}

Goroskieta Estella, P. y Sánchez-Dehesa Galán, C. (2015). “Creación de una filmoteca de prácticas para la Facultad de Ciencias de la Información de la UCM: Adecuación de espacio y estrategias de catalogación”. Documentación de las Ciencias de la Información, Vol. 38: páginas 179-202
\end{abstract}




\section{INTRODUCCIÓN}

La preservación de nuestro Patrimonio cinematográfico es esencial. La velocidad de cambio que vivimos es cada vez más rápida y no da tiempo a que la sociedad sea consciente de la urgente necesidad de preservar estos materiales. Aunque sea relativamente joven, envejece rápido, y por ello no puede ser olvidado.

Gracias a instituciones como la Federación Internacional de Archivos Fílmicos $(\text { FIAF })^{1}$, creada por un conjunto de archivos que luchan por los mismos objetivos: recuperar, coleccionar, preservar y proyectar imágenes en movimiento, se sigue trabajando en una filosofía y unas normas comunes para todas las instituciones fílmicas.

Uno de los pasos más importantes que hay que dar es la profesionalización de los especialistas en esta área. No sólo es necesario el plantear un sistema normativo común, sino conseguir un mayor reconocimiento a una enseñanza a la que se le da poca importancia. La falta de especialistas y la desvalorización de la profesión no ayudan a la preservación en nuestro patrimonio fílmico.

En materia de archivos fílmicos. España parece seguir la dinámica del maestro y el aprendiz. Teniendo en cuenta las nuevas estructuras laborales y educativas, no se dispone de tiempo suficiente para que este sistema de aprendizaje sea efectivo. Hay que combinarlo con una buena base formativa, que ya está definida e implantada por otros países.

Este trabajo recoge directamente una propuesta que complemente al Master de Patrimonio Audiovisual: Historia, Gestión y Recuperación, única oferta formativa de nivel universitario que existe hoy en día, y que puede convertirse en referente en la formación en preservación fílmica dentro de nuestro país.

\section{OBJETIVOS Y METODOLOGÍA}

Dos de las palabras clave que están incluidas en el título del máster son gestión y recuperación, palabras en las que se fundamenta este trabajo. La idea principal que se plantea es la de crear una Filmoteca de Prácticas para que futuros alumnos e investigadores tengan la posibilidad de conocer, practicar, estudiar y disfrutar con material fílmico.

Al comprobar la carencia de contenido práctico en el máster, se analizó la posibilidad de realizar un trabajo de investigación final que ayudase a que otros alumnos tengan la posibilidad de conocer, practicar y aprender a partir de esta Filmoteca. De esta forma se crea un espacio para la práctica y el contacto del usuario con material fílmico. Para ello había que realizar una serie de tareas previas:

- Estudio de las condiciones del espacio donde se va a almacenar el material fílmico.

${ }^{1}$ ¿Qué es la FIAF? http://www.fiafnet.org/es/whatis.html 
- Limpieza del espacio de material que se considera roto e inservible. Se consigue mayor amplitud y movilidad para trabajar cómodamente.

- Creación de un inventario de la colección con el que poder conocer la magnitud de los fondos, su estado de conservación y el tipo de material. Gracias a este informe se hace una primera ordenación de las películas pero el orden no es definitivo. Se analiza cada lata y rollo fílmico, recogiendo la información que se ha considerado más importante para el trabajo posterior.

- Planteamiento y diseño del espacio para una mejor conservación, recaudación de material como estanterías y mesas en las que poder trabajar y propuesta de material necesario para que los futuros usuarios trabajen correctamente. Se rescata del sótano de la facultad antiguo material que aunque en principio se dio de baja, se cree puede ser de nuevo funcional.

- Establecimiento de las necesidades ambientales de los materiales que forman la colección para su buena conservación en el tiempo.

- Se consigue la colaboración del departamento de mantenimiento de la facultad, que facilita la búsqueda de mobiliario para el espacio y la incorporación de otros materiales a la colección.

Este trabajo previo ayuda a valorar el estado de los fondos y el espacio para poder empezar a trabajar con él en la creación real de esta Filmoteca de Prácticas de la Facultad de CCINF de la UCM.

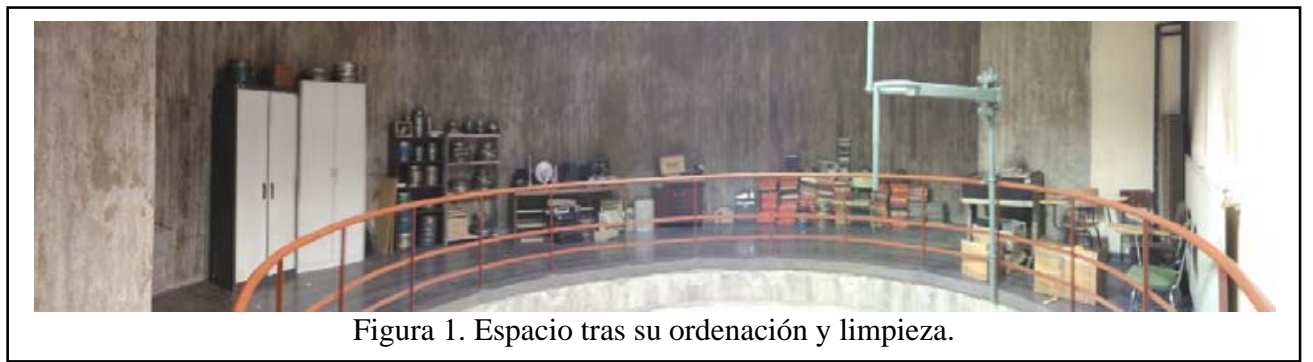

\subsection{Catalogación y ordenación de los fondos fílmicos}

Se debe trazar un plan de catalogación y base de datos que se adapte a la labor que se va a desarrollar en este trabajo. Se establecen las bases para el estudio, catalogación y descripción del patrimonio cinematográfico encontrado en la facultad de CCINF de la UCM, tomando como referente las normas ya existentes y sancionadas por la práctica de uso en instituciones cinematográficas.

Dichas normas nos proporcionan un nivel de seguridad con la que se establece una base para la enseñanza e investigación, abierta a cambios que se adapten mejor a lo que aquí interesa crear y organizar. El proceso de documentación de los materiales conservados en este archivo constituye un paso importante en su estudio para todo 
aquel que esté interesado, principalmente alumnos y profesores del centro en el que se va a desarrollar, e investigadores que quieran formar parte.

Se va a intentar proporcionar una aproximación coherente a la catalogación del material lo más descriptiva posible, que sea accesible y adaptada. Se van a tener en cuenta las funciones que este catálogo va a permitir en el correcto manejo del usuario:

- Localizar uno o varios recursos.

- Identificar el material.

- Seleccionar las búsquedas.

- Adquirir acceso al material localizado bajo el cumplimiento de algunas normas.

- Navegar por el catálogo.

Es necesario que la base de datos que se cree a partir de todo el trabajo de investigación previo de estos fondos tenga una persona a su cargo que pueda enseñar cómo manejar la búsqueda y sirva de apoyo para que puedan llevarse a cabo futuros trabajos de investigación. Se creará un espacio gratuito, accesible y de fácil manejo especializado. Se debe ofrecer al usuario un servicio de consulta de los materiales en el que los encargados puedan ofrecer un servicio correcto de asesoría y manejo para facilitar la búsqueda del objeto de investigación.

Es necesario también plantearse algunos objetivos a alcanzar. No hay que olvidar que pueden contradecirse y plantearse algunos nuevos que se adapten en el proceso de creación. En estos casos, se hará un nuevo planteamiento con el fin de alcanzar un perfil adecuado.

- Adaptación al interés del usuario. Hay que ser consciente de los diferentes perfiles de usuarios que van a poder acceder a la base de datos.

- Creación de un vocabulario de uso común que se adapte al perfil de todos los usuarios.

- Normalización en las descripciones. Hay que ser lo más fiel posible al sistema de normas que entidades y organismos han creado para el correcto manejo y entendimiento.

- Integración del material en base al sistema común de reglas, hasta donde sea posible.

- Necesidad de crear un archivo audiovisual que facilite el acceso para la visualización y estudio del material.

- Análisis de la información, clasificación y descripción lo más detallada posible.

Los organismos internacionales como la FIAF, UNESCO, CCAAA ${ }^{2}$, IASA ${ }^{3}$, entre otros, han tratado la búsqueda de una solución común para una correcta catalogación de este material.

${ }^{2}$ Coordinating Council of Audiovisual Archives Associations 
A día de hoy siguen haciéndolo adaptando las normas a la nueva era audiovisual. En este trabajo se profundiza en los análisis normalizados de catalogación propuestos por IFLA (FRBR) ${ }^{4}$ o FIAF, los cuales se toman como ejemplo para la realización y propuesta de un modelo de catálogo automatizado adaptado a la Filmoteca de Prácticas. Las directrices que marca la FIAF deben ser usadas de forma correcta. Son bases estándar y comprensibles, lo cual parece que se ha convertido en un reto en lo que a archivos fílmicos respecta, por lo que se espera con ello un cierto grado organizativo. En cambio las directrices que marca el modelo FRBR es más complejo y está adaptado al mundo digital donde se crean nuevas categorías adaptadas a los nuevos medios. Sirven para identificar y relacionar cualquier documento que se pueda encontrar hoy en día en un sistema documental.

Cabe destacar otras normas interesantes como las normas UNE-EN 15744:2011 y UNE EN 15907:2011, que definen un conjunto de metadatos para la descripción de la obra cinematográfica. Se emplea una terminología específica para poder llevar a cabo este sistema descriptivo. De esta forma se hace necesaria una estandarización en la base de datos para una mejor estructura descriptiva de estos materiales fílmicos. Para tener acceso al uso de esta marca se concede una certificación de productos y sistemas de gestión. Es conveniente fijarse en los informes anuales de las diferentes instituciones que se ponen a disposición en la página oficial de la FIAF para tomar como ejemplo para la elaboración de un futuro informe completo de catalogación de todos los fondos existentes en el espacio.

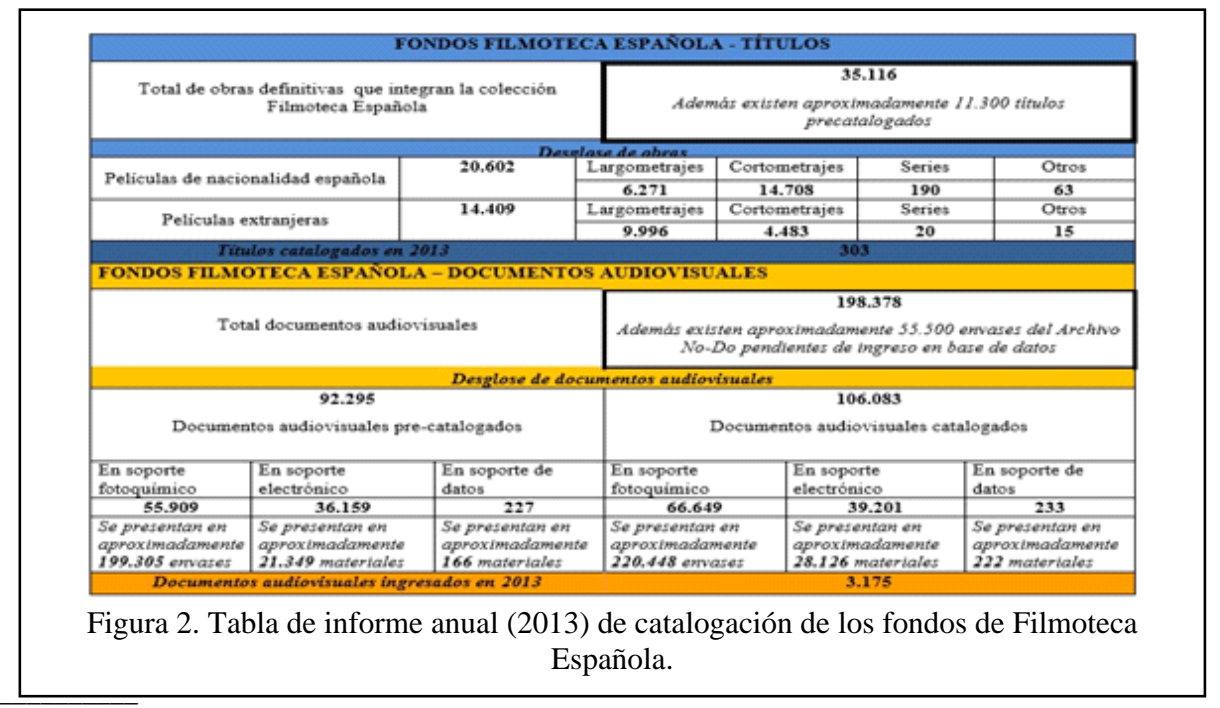

\footnotetext{
${ }^{3}$ International Association of Sound and Audiovisual Archives

${ }^{4}$ Principios de catalogación de IFLA: pasos hacia un código internacional de catalogación http://www.ifla.org/files/assets/cataloguing/icc/ime-icc-1-es.pdf
} 
En red existen diferentes estilos de páginas que ponen a disposición del usuario un espacio de creación de bases de datos adaptadas. Algunas de ellas son Collective Access, DSpace, Koha, Meran, Arcadia o AVCC Inventory\&Collection Management Tool. La parte descriptiva debe basarse en las normas internacionales que la FIAF propone y adaptarlas al espacio que se está creando. Por ello, y tras analizar las diferentes propuestas de bases de datos en línea, la más accesible y adaptada a las necesidades de lo que se está creando en la Filmoteca de prácticas es la propuesta de AVCC cataloguing ${ }^{5}$, perfecta para la catalogación de colecciones audiovisuales con un formato adaptado a un documento Excel.

En el año 2003 la IFLA redacta unos nuevos principios de catalogación ante la urgente necesidad de una evolución. Se reformulan los cinco objetivos básicos que un catálogo debería permitirnos:

- Encontrar/Localizar un solo recurso o un conjunto de recursos.

- Identificar un documento por medio de un registro

- Seleccionar/Elegir un registro que se adapte a la búsqueda realizada por el usuario. En este paso debería darse ya la suficiente información que ayude a seleccionar o descartar datos.

- Adquirir u obtener acceso al documento. Se da la información necesaria para su localización y obtención.

- Navegar por el catálogo o base de datos de manera intuitiva.

Existe una necesidad de crear espacios virtuales de almacenamiento de datos. Este nuevo sistema, adaptado a los nuevos tiempos de catalogación, tiene varias ventajas como el ahorro del espacio al quedar la información almacenada en un ordenador. Los usuarios acreditados para llevar a cabo el proyecto de continuación de la Filmoteca serán los únicos acreditados para modificar, actualizar o eliminar el contenido de la base de datos. Debe estar todo almacenado en la memoria de uno o varios ordenadores y por la seguridad y supervivencia de estos datos deben ser subidos a una nube. La ventaja que el mundo tecnológico nos abre puede convertirse a su vez en una desventaja si este contenido no es puesto a salvo.

Al tener ya un primer informe de catalogación de los fondos se puede empezar a pensar en una estructura lógica y física de diseño de base de datos y adaptada al usuario. El archivo con el que se está trabajando es muy variado por lo que los campos de información son amplios. Debe ser una estructura clara, descriptiva y bien definida para que la búsqueda resulte cómoda y exitosa.

\footnotetext{
${ }^{5}$ https://avcc.avpreserve.com/
} 


\section{LA COLECCIÓN DE LA FILMOTECA DE PRÁCTICAS DE CIENCIAS DE LA INFORMACIÓN}

El proceso de creación de la filmoteca de prácticas comienza tras la localización, por parte del profesor Félix del Valle Gastaminza, de varias latas de película y otros materiales de imagen y sonido abandonados en el aula número 217 de la Facultad de Ciencias de la Información de la Universidad Complutense de Madrid.

El espacio muestra un aspecto de dejadez y acumulación de polvo fruto del paso del tiempo. Es evidente el estado de abandono. Tras la ordenación del material y limpieza del lugar se realiza un primer informe en el que se describe el material fílmico encontrado. Este primer paso sirve como toma de contacto y conocimiento previo hacia lo que se va a documentar e investigar. Los materiales audiovisuales que se van a describir y catalogar son principalmente de paso $16 \mathrm{~mm}$ y $35 \mathrm{~mm}$.

El recuento total que se hace en un principio es de 465 películas en latas metálicas, de plástico, de cartón y otras sin envase. 88 son de $35 \mathrm{~mm}, 377$ son de $16 \mathrm{~mm}$ y 1 cinta magnética de tres octavos. El recuento se ve alterado más tarde al ser seguida una pista muy importante en la que se localizan 5 latas más de películas, el mes de junio, en la antigua videoteca de la facultad y que en su día custodiaba José Luis Sevilla. El recuento en este momento es de 470 películas. No se descarta que en algún futuro aparezcan más latas en algún otro rincón de la facultad o lleguen donaciones en otros pasos y formatos. El informe redactado hasta el momento se va a considerar definitivo.

No sólo se hallan latas de películas. La mitad de este espacio es material de sonido (en su gran mayoría magnético de diferentes pulgadas, siendo la más común de $1 / 2$ pulgada), cintas en soporte de $3 / 4$ de pulgada conocido comúnmente como U-matic y antiguos equipos tanto de reproducción de sonido como de video dados de baja en su gran mayoría o estropeados (esto se indica mediante etiquetas escritas a mano en los propios equipos dados de baja). Pero en esta primera fase de creación se ha decidido dejar esta parte de los fondos para un futuro trabajo de investigación y centrarse en el origen y catalogación de las películas.

Esta colección constituye un núcleo importante. Se trata de un archivo en el cual encontramos películas provenientes de diferentes personas vinculadas en su día a la UCM y lugares de donde fueron rescatadas. La variedad de etiquetas con nombres de importantes laboratorios cinematográficos y productoras de diferentes países le dan mayor valor a lo que aquí se va a investigar.

En las latas se ha encontrado una numeración manual mediante etiquetas o escrito en la propia lata a mano, la cual parece ha sido dada una vez la colección estaba ya formada. La razón por la que se llega a esta conclusión es porque esta numeración la presentan más del 80\% de las latas, desde el 1 hasta el 396. Aunque no se ha comprobado que estén todos los números debido a que hay etiquetas que pueden haberse perdido o están dentro del propio envase. Las latas no estaban colocadas siguiendo el orden en todo momento, aunque hay tramos donde sí que se respeta dicho orden.

Los documentos audiovisuales que se encuentran en esta colección son en soporte de acetato. En el caso de que se hubiese encontrado material en soporte de nitrato 
inmediatamente se haría la obligada donación a Filmoteca Española, que debido a su fragilidad e inestabilidad está establecido preservar estas películas en un lugar debidamente aclimatado y controlado. Pero una vez conocida la historia y orígenes del material era altamente improbable encontrar este tipo de soporte entre todas las películas de la colección.

El archivo se complementa con otros documentos físicos como carteles, fotografías, material sonoro, otros formatos de imagen, material de proyección, etc., que constituye la base de este archivo gráfico. Pero esta primera fase de investigación no se va a centrar en estos documentos.

Se hace una división escrita en cuatro partes o armarios. No se mueve ninguna película de sitio en esta primera fase de catalogación. Pero con la obtención de mobiliario se intenta seguir con el orden de catalogación seguido hasta el momento. Para una mejor identificación y reconocimiento de las diferentes etiquetas y productoras que han ido apareciendo se las divide por colores en el informe.

Hay un total de 7 productoras fácilmente identificables y destacables por la etiqueta identificativa que muestran en su gran mayoría en el exterior de la lata. En negro se dejan las que no llevan una identificación tan clara, son prácticas de alumnos, copias sueltas o no se sabe su procedencia hasta que no se realice una completa investigación.

\begin{tabular}{|l|l|l|}
\hline \multicolumn{1}{|c|}{$\begin{array}{c}\text { LEYENDA } \\
\text { COLORES } \\
\text { POR ETIQUETA }\end{array}$} & \multicolumn{1}{c|}{ PRODUCTORA } \\
\hline & Verde & Exclusivas y Representaciones Pons. 4 películas de 16mm. \\
\hline & Rojo & $\begin{array}{l}\text { Antonio Morales Producción y Distribución. } 45 \text { películas } \\
\text { de 16mm. }\end{array}$ \\
\hline & Azul & Filmoteca Movinter. 119 películas de 16mm y 7 de 35mm. \\
\hline & Amarillo & $\begin{array}{l}\text { Deutschlandspiegel y DRF Deutsche reportagefilm. } 127 \\
\text { películas de 16mm y 3 de 35mm. }\end{array}$ \\
\hline & Morado & Fotofilm Madrid S.A. 7 películas de 16mm y 13 de 35mm. \\
\hline
\end{tabular}




\begin{tabular}{|l|l|l|}
\hline Rosa & $\begin{array}{l}\text { Cinematiraje Riera s.a. Laboratorio Cinematográfico. } 18 \\
\text { películas de } 35 \mathrm{~mm} .\end{array}$ \\
\hline Naranja & $\begin{array}{l}\text { Image Film. Laboratorio Cinematográfico. } 5 \text { películas de } \\
35 \mathrm{~mm} .\end{array}$ \\
\hline Negro & $\begin{array}{l}\text { Películas y etiquetas sueltas, escritas a mano o sin } \\
\text { Identificación.74 películas de } 16 \mathrm{~mm} \text { y } 44 \text { de } 35 \mathrm{~mm} .\end{array}$ \\
\hline
\end{tabular}

Tabla 1. Leyenda de colores por productoras.

La parte de los fondos sobre la que se va a investigar se compone de copias de películas y documentales comerciales en $16 \mathrm{~mm}$ y $35 \mathrm{~mm}$ fechados en su gran mayoría en las décadas de los años sesenta y setenta. Se aprecia alguna excepción, como prácticas de alumnos de finales de los ochenta. Hay bobinas y latas que no llevan identificación visible y que sería conveniente estudiar el contenido para tener una mayor aproximación a su historia y procedencia.

Se han seguido varias pistas aportadas por personas que en su día formaron parte del equipo docente de la facultad y que han llevado a relacionar gran parte del fondo con entidades y personas externas a la UCM. Se convierte en una interesante investigación que acaba por poner en relación instituciones tanto nacionales como extranjeras.

La primera acción que se hace una vez redactado el informe de catalogación es contactar con Gilles Multigner (antiguo docente de la CCINF y BBAA, ya jubilado). La idea es que pudiera aportar datos relevantes y tras una reunión en la que se le muestra el lugar físico donde se albergan, comienzan a aparecer los primeros nombres significativos: Se menciona a Ingrid Schulze Schneider del Departamento de Historia de la Comunicación Social cuyos trabajos de investigación, en los que trata sobre la propaganda política y de guerra alemana la pone en relación con la embajada Alemana, de donde proceden varios de los fondos documentales. Las latas cuya etiqueta corresponde a Deutschlandspiegel y DRF Deutsche reportagefilm o se lee Nacionalidad alemana proceden efectivamente de la embajada Alemana (muchas de las película de Filmoteca Movinter o Antonio Morales distribuyen copias de estas películas). Se hace una lista con estos nombres y se investiga su vinculación. Los boletines y documentales se enviaban a las distintas embajadas de varios países para mostrar y publicitar la República Federal Alemana. Se distribuían en formato $16 \mathrm{~mm}$ y no duraban más de 15 minutos. Se sabe que en Filmoteca Española existen copias de estos boletines mensuales. Surge también el nombre de Lorraine Choquette (Agregada política y de comunicación de la embajada canadiense) quien entrega a Filmoteca Española un fondo películas de la embajada Canadiense, que previamente estuvieron en la facultad de Ciencias de la Información como puede leerse en un informe de donación a esta 
institución del año 1992, por lo que queda aclarado el misterio de las latas de películas que nunca llegaron al aula 217. Se barajan otros nombres como Juan José Porto (escritor, guionista y director de cine) o José Antonio Jiménez de las Heras (profesor y doctor de la UCM) entre otros. Se propone buscar en otros espacios de la propia facultad ante la posibilidad de encontrar latas de películas que faltan en el aula, dando como resultado un nuevo descubrimiento: En la antigua videoteca, de la que se encargaba José Luis Sevilla, se localizaban algunas latas con copias de películas que fueron depositadas en los depósitos de la Biblioteca de la Facultad al desaparecer la videoteca. Estas películas son obra del realizador independiente Gabriel Blanco del Castillo. Fue profesor de realización en CCINF y tras su repentina muerte en 1991 se depositó su colección personal en la videoteca, pero el paso del tiempo las dejó en el olvido. Este descubrimiento abre paso a nuevas líneas de investigación. Las películas que se localizan de este realizador constituyen casi toda su obra como director. De las siete películas que dirige y escribe hay dos títulos que no están en el hallazgo: La Edad de la piedra y De purificatione automobilis. Las que si aparecen son Cualquier Mañana (1970), Algo de Amor (1973), Vía Libre al Tráfico (1975), La Edad del Silencio (1978) y Felicidad (1980).

\section{EL CATÁlOGo DE LA FILMOTECA DE PRÁCTICAS DE LA FACULTAD DE CIENCIAS DE LA INFORMACIÓN}

Se crean varios formularios para la catalogación, inspección y visionado adaptados a la filmoteca de prácticas para los cuales se han analizado previamente los ofrecidos por diferentes filmotecas e instituciones. En ellos debe recogerse la información necesaria que ayude en la identificación y ordenación de la colección. Es una información básica y adaptada a los fondos que se encuentran, por lo que si llegan nuevos fondos cuya identificación no se adapte a estos informes, debe ser ampliada y contrastada.

Se hace una primera catalogación dividida en diferentes puntos que se consideran de importancia para una rápida identificación previa de la que poder crear en un futuro una nueva base más detallada y definida para el usuario.

- Armario: Se definen cinco armarios en orden de izquierda a derecha según se accede.

- Posición: Número de posición que se da a la película en un orden establecido.

- Envase: Forma y material de la lata.

- Bobinado: Si la película va bobinada en núcleo, en bobina o no tiene núcleo.

- Longitud: Metros totales de metraje.

- Paso: Por el momento sólo hay de $16 \mathrm{~mm}$ o $35 \mathrm{~mm}$.

- Tipo de material: Si es sonido, sólo imagen o copia compuesta.

- Tipo de imagen: Color, Blanco y Negro o sin imagen.

- Sonido: Magnético, Óptico de Área Variable, Dolby Digital o sin sonido.

- Etiqueta lata: Toda información que se lea en la lata.

- Anotaciones y pegatina lata: Información extra en laterales o dentro de la lata. 
Para la realización de estos informes se han llevado a cabo varios pasos importantes para adaptar una descripción y valoración lo más fiel posible. Se considera necesario dar algunas pautas y consejos de cómo rellenar los informes para conseguir una mayor eficiencia y claridad para que otros usuarios puedan entender la información con facilidad.

- Fijarse bien en las descripciones de las etiquetas que se muestran en las latas. No siempre coincide el contenido con lo que leemos. Y en algunos casos puede darse información extra en etiquetas sueltas y guardadas en el interior. O pueden darse títulos alternativos escritos en la propia guía adherida al principio y al final de la película.

- Importante. Antes de pasar al visionado, describir y anotar bien cada etiqueta e información extra. También es aconsejable valorar su estado a primera vista. Pueden encontrarse empalmes sueltos, roturas de perforaciones que deben ser reparadas, etc. Es obligatorio revisar la película en una moviola manual para evitar roturas mayores por el tirón mecánico de los rodillos al tensar. Una perforación rota puede ocasionar un daño mayor e irreparable.

- Visionado. Una vez valorado el estado físico y reparado lo que se considere necesario puede por fin hacerse el visionado de la película. Es aconsejable anotar si las imágenes coinciden con lo descrito en las etiquetas, y en el caso de que no se disponga de una información previa anotar toda información necesaria que nos aporten las imágenes para poder llegar a identificar su contenido.

- Debe anotarse también cualquier síntoma de deterioro en la imagen que se aprecie en el visionado como la pérdida de color y emulsión, rayas tanto profundas como superficiales, suciedad, manchas, etc. Cualquier dato que se aporte sobre su estado es importante.

A continuación se pone como ejemplo los informes de visionado de una de las películas seleccionadas al azar en los que se determina su estado físico y el contenido argumental de la copia para una supuesta catalogación y documentación:

- Descripción en etiqueta: Productora embajada alemana Deutsche Reportagefilm. 16mm. Kopie Nr 14. Escrito en etiqueta 345.

- Notas de visualización: Escrito en guía con rotulador “Portraits: Jahn”, Minister Jahn. Película muda en $\mathrm{B} / \mathrm{N}$.

- Contenido: Nombramiento del señor Gerhard Jahn el 22 de octubre 1969 como Ministro Federal de Justicia a Alemania Occidental en la nueva Canciller de la coalición social liberal, Willy Brandt. Se muestran momentos antes de la ceremonia de elección y el momento en el que es nombrado Ministro.

- Estado físico: Se valora un buen estado en general. Parece que apenas ha sido proyectada con anterioridad. Una única rotura al principio de la película. 


\section{FILMOTECA DE PRÁCTICAS UCM - INFORME DE CATALOGACIÓN}

$\mathrm{N}^{\circ}$ LOC: 4A Posición 38

$\mathrm{N}^{\circ}$ REF.: 345

TÍTULO ORIGINAL: Sin título

TÍTULO EN COPIA: Sin título

TÍTULO ALTERNATIVO: Portraits:Jahn / Minister Jahn

AÑO DE ESTRENO/ PUBLICACIÓN: 1969.

AÑO DE PRODUCCIÓN: 1969.

PRODUCTORA: Deutsche Reportagefilm PAÍS: Alemania

COLECCIÓN: Deutsche Reportagefilm. Embajada Alemana.

DIRECTOR /A: Embajada Alemana. Oficina de Prensa.

OTROS NOMBRES RELEVANTES: Ministro Jahn.

DERECHOS DE AUTOR: No consta.

Información obtenida de: etiqueta adherida a la lata, título escrito a mano en guía.

PROCEDENCIA: Embajada alemana

TIPO DE ADQUISICIÓN:

Donación

\begin{tabular}{|l|l|l|l|}
\hline SOPORTE & Triacetato & EMULSIÓN & $\begin{array}{l}\text { Blanco y } \\
\text { Negro }\end{array}$ \\
\hline PASO & $16 \mathrm{~mm}$ & SONIDO & Sin sonido \\
\hline ELEMENTO & & N $^{\circ}$ ROLLOS & $1 / 1$ \\
\hline METRAJE & $45 \mathrm{~m}$ & FORMATO & $\begin{array}{l}\text { Normal } \\
1: 1^{\prime} 33\end{array}$ \\
\hline IDIOMA & Alemán & SUBTÍTULOS & No \\
\hline INTERTÍTULOS & No & & \\
\hline
\end{tabular}

Identificar entre: Excelente / Buena / Mediocre / Mala

\begin{tabular}{|l|l|}
\hline CONDICIÓN FÍSICA & Buena \\
\hline CALIDAD ÓPTICA & Buena \\
\hline CALIDAD SONORA & Buena \\
\hline
\end{tabular}

NOTAS: única rotura al principio, posiblemente sea rotura de proyección. 
FILMOTECA DE PRÁCTICAS UCM - INFORME DE VISIONADO

$\mathrm{N}^{\circ}$ LOC: 4A Posición 38

$\mathrm{N}^{\circ}$ REF.: 345

TíTULO: Portraits:Jahn / Minister Jahn (Título alternativo).

\begin{tabular}{|l|l|l|l|}
\hline SOPORTE & Triacetato & EMULSIÓN & $\begin{array}{l}\text { Blanco y } \\
\text { Negro }\end{array}$ \\
\hline PASO & $16 \mathrm{~mm}$ & SONIDO & $\begin{array}{l}\text { Sin soni- } \\
\text { do }\end{array}$ \\
\hline FORMATO & Normal 1:1’33 & IDIOMA & Alemán \\
\hline INTERTÍTULOS & No & SUBTÍTULOS & No \\
\hline
\end{tabular}

\begin{tabular}{|l|l|l|l|}
\hline $\mathbf{N}^{0}$ ROLLOS & $1 / 1$ & METRAJE & $45 \mathrm{~m}$. \\
\hline VEL. PROJ. & $24 \mathrm{fp}$ & TIEMPO & $\begin{array}{l}4 \mathrm{minu}- \\
\text { tos } 28 \\
\text { segundos }\end{array}$ \\
\hline
\end{tabular}

Identificar entre: E - Excelente / B - Buena / M - Mediocre / P Pobre

\begin{tabular}{|l|l|l|l|l|l|l|l|l|}
\hline & $\mathbf{1}$ & 2 & 3 & 4 & 5 & 6 & 7 & 8 \\
\hline CONDICIÓN FÍSICA & B & & & & & & & \\
\hline CALIDAD ÓPTICA & B & & & & & & & \\
\hline CALIDAD SONORA & B & & & & & & & \\
\hline
\end{tabular}

\section{NOTAS AL VISIONADO:}

Se valora un buen estado en general. Parece que apenas ha sido proyectada con anterioridad. Una única rotura al principio de la película que no afecta al visionado.

\section{PROBLEMAS EN VISIONADO:}

Perfecta reproducción en el visionado.

CONDICIÓN GENERAL: Copia en buen estado. 


\section{MATERIALES QUE CONFORMAN LA FILMOTECA DE PRÁCTICAS DE LA FACULTAD DE CIENCIAS DE LA INFORMACIÓN}

\begin{tabular}{|c|c|c|}
\hline Material & Tipo & Cantidad \\
\hline \multicolumn{2}{|l|}{ Latas no abiertas } & 6 \\
\hline Soporte & Acetato & 470 \\
\hline \multirow[t]{4}{*}{ Envase } & Cartón & 47 \\
\hline & Metálico & 262 \\
\hline & Plástico & 152 \\
\hline & Sin envase & 7 \\
\hline \multirow[t]{3}{*}{ Bobina o núcleo } & Bobina & 350 \\
\hline & Núcleo & 100 \\
\hline & Nada & 14 \\
\hline \multirow[t]{4}{*}{ Metraje $16 \mathrm{~mm}$} & $0-120 \mathrm{~m}$ & 91 \\
\hline & $120-360 \mathrm{~m}$ & 176 \\
\hline & $360-600 \mathrm{~m}$ & 58 \\
\hline & $600-1600 \mathrm{~m}$ & 46 \\
\hline \multirow[t]{3}{*}{ Metraje $35 \mathrm{~mm}$} & $0-300 m$ & 16 \\
\hline & $300-600 \mathrm{~m}$ & 66 \\
\hline & $600-1200$ & 5 \\
\hline \multicolumn{2}{|l|}{ Magnético 1/4 } & 1 \\
\hline \multirow[t]{3}{*}{ Paso } & $16 \mathrm{~mm}$ & 380 \\
\hline & $35 \mathrm{~mm}$ & 88 \\
\hline & Otro & 1 \\
\hline \multirow[t]{5}{*}{ Elemento } & Colas & 3 \\
\hline & Copia compuesta & 398 \\
\hline & Imagen Positiva & 24 \\
\hline & Imagen Negativa & 9 \\
\hline & Sonido & 14 \\
\hline \multirow[t]{2}{*}{ Imagen } & Blanco y negro & 87 \\
\hline & Color & 344 \\
\hline \multirow[t]{3}{*}{ Sonido } & Óptico & 390 \\
\hline & Magnético & 36 \\
\hline & Combinados & 1 \\
\hline
\end{tabular}


La principal conclusión con respecto a los materiales, es que la totalidad de los mismos presentan soporte acetato, priman las películas con emulsión de color tricapa y el sonido óptico.

Además de esto, del cuadro se deduce que:

- La homogeneidad de soporte reduce el abanico de condiciones ambientales a las que hay que adaptarse, aunque el acetato de celulosa presenta unas necesidades de conservación muy exigentes, por ser un material bastante sensible.

- A esto se une que los materiales con emulsión en color tricapa son previos a 1970, muy sensibles a la decoloración y que necesitan también unas condiciones de conservación muy específicas.

- Prácticamente la totalidad de los materiales se encuentra protegido de alguna forma frente a golpes, suciedad y cambios ambientales.

- Aunque sólo hay 14 materiales sin bobina o núcleo donde enrollarse, se considera urgente dotarles de uno u otro elemento para su mejor conservación.

- La colección presenta muy pocos elementos originales o de producción, por lo que se asume que no estamos trabajando con materiales únicos.

\section{ANÁLISIS DE LAS CONDICIONES ES DEL ESPACIO DESTINADO A LA FILMOTECA DE PRÁCTICAS}

La colección se hallaba en el aula 217 de la Facultad de Ciencias de la Información de la UCM. Este espacio no es un aula como tal. Se encuentra en el interior de uno de los torreones que cierran la parte trasera del edificio antiguo. El espacio está conectado a otro inferior, donde se ubica el departamento de tecnología, a través de un gran agujero central protegido por una barandilla. El techo no está totalmente cubierto, existe un lucernario circular sobre el agujero central.

Este espacio, en conjunto con el situado inmediatamente debajo, parece que fue concebido para una emisora de radio. De hecho, queda aún la antigua antena de radio. Ventajas:

- Se trata de un espacio que, actualmente, tiene capacidad suficiente para almacenar la colección de la Filmoteca de Prácticas, incluso para aumentarla hasta doblar su tamaño actual.

- Se pueden incluir dentro de este espacio un par de mesas de trabajo para desarrollar en el mismo las labores de revisión y catalogación. Esto puede ser una ventaja, en el caso de que se consigan mejorar las condiciones de almacenamiento, puesto que no es necesario aclimatar los materiales al espacio de trabajo antes de inspeccionarlos.

- Presenta una entrada independiente con puerta cerrada con llave, por lo que el acceso está controlado.

- Al tratarse de un diseño circular, las paredes presentan pocos rincones donde pueda acumularse polvo y suciedad, por lo que la limpieza puede facilitarse. 
Inconvenientes:

- Presenta luz natural constante que, aunque no incide directamente sobre los materiales, no puede ser bloqueada o tamizada fácilmente.

- Actualmente no dispone de instalación eléctrica útil, lo cual impide el uso de cualquier aparato que necesite de ello.

- Existe iluminación artificial halógena, que se enciende desde el espacio inferior, donde trabajan los técnicos.

- La ventilación que presenta viene por las ventanas que presenta el espacio inferior de los técnicos, a las que sólo ellos tienen acceso.

- No existe ningún tipo de control climático, aunque si dos radiadores grandes, que parecen haber estado en funcionamiento (por las marcas de suciedad que presenta la pared en la zona que les rodea). Probablemente el control de estos radiadores se haga desde las instalaciones centrales de la facultad, y no es seguro que pueda manipularse para conseguir una temperatura personalizada.

- El gran agujero central, que une los espacios inferior y superior hace que el mantenimiento de la limpieza sea complejo, puesto que las partículas de polvo pueden moverse de un espacio al otro fácilmente.

- Al igual que no existe sistema de control de temperatura, no existe posibilidad de control de humedad relativa. Unido al espacio inferior, se trata de un área muy grande, y el uso de aparatos de humectación o deshumectación del ambiente tendrían que trabajar con muchos más metros cúbicos de los que realmente ocupa la colección.

- Las paredes del espacio son de cemento, sin recubrimiento. Presenta una terminación rugosa e irregular que facilita el depósito de partículas de suciedad ambiental y dificulta la limpieza.

El edificio de la Facultad de Ciencias de la Información está orientado, en su parte trasera hacia el oeste, por lo tanto, le afecta principalmente el sol de la tarde. Hay que tener en cuenta que el lucernario permite la entrada de sol directo en las horas centrales del día, por lo tanto, las horas de incidencia directa de luz solar y calor aumentan con respecto a otras áreas del edificio.

Las condiciones de temperatura y humedad que presenta no han podido ser monitorizadas, por falta de equipos y de tiempo, pero se ha hecho un estudio de estas variables en la ciudad de Madrid, para poder establecer unos puntos de referencia sobre los que trabajar. 

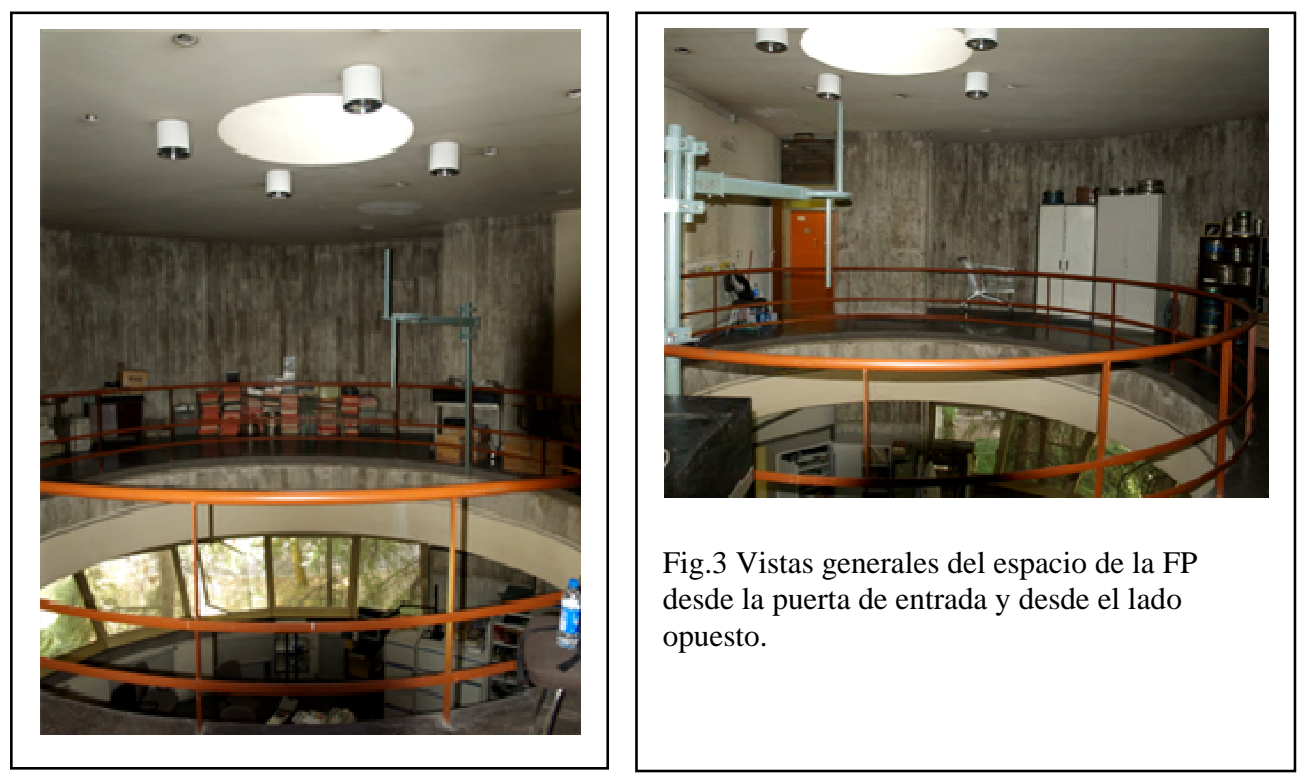

Por todo lo dicho anteriormente, se presupone que el espacio de almacenamiento va a presentar unas condiciones muy similares a las exteriores, quizás con una variación de algunos grados en la temperatura. Las condiciones de humedad relativa se pueden considerar las mismas, puesto que los muros del espacio son los de cierre del edificio.

La media de temperatura se ha estimado entorno a los $20^{\circ} \mathrm{C}$, con unas variaciones medias de entre 5 y $6^{\circ} \mathrm{C}$. Hay que asumir que en invierno la calefacción estaría encendida, y se mantendría a esta temperatura. El punto más crítico se alcanzaría en verano, donde se ha visto que se llegan fácilmente los 30 grados y no hay ningún tipo de refrigeración controlada, mucho menos en el mes de agosto cuando el edificio permanece cerrado. La humedad relativa se mantiene todo el año en torno al 50\%, bajando en los meses de verano ${ }^{6}$.

La parte trasera del edificio está rodeada de una gran arboleda, lo cual, por un lado, puede suavizar la temperatura ambiental, reduce la incidencia directa de sol y regula la humedad relativa. Pero a su vez, se trata de un posible foco de contaminación biológica que puede acceder al área de almacenamiento.

A partir del estudio de los textos del Image Permancence Institute (IPI) y los diversos estándares ISO para materiales fílmicos, hemos establecido que los factores más importantes a controlar para alargar la vida de los materiales que conforman el patrimonio audiovisual son los siguientes: temperatura, humedad relativa y contaminantes.

La relación de temperatura y humedad relativa que recomienda los estándares para los materiales que encontramos en la Filmoteca de prácticas son:

${ }^{6}$ Datos obtenidos de AEMET. 


\begin{tabular}{|l|l|l|}
\hline MATERIAL & TEMPERATURA MAX. & HUMEDAD REL. MAX. \\
\hline Soporte acetato & $2^{\circ} \mathrm{C}$ & $50 \%$ \\
Imagen blanco y negro $^{7}$ & $5^{\circ} \mathrm{C}$ & $40 \%$ \\
& $7^{\circ} \mathrm{C}$ & $30 \%$ \\
\hline Soporte acetato & $-10^{\circ} \mathrm{C}$ & $50 \%$ \\
Imagen color $^{8}$ & $-3^{\circ} \mathrm{C}$ & $40 \%$ \\
& $2^{\circ} \mathrm{C}$ & $30 \%$ \\
\hline Soporte acetato $^{\text {Emulsión magnética }}{ }^{9}$ & $11^{\circ} \mathrm{C}$ & $50 \%$ \\
& $17^{\circ} \mathrm{C}$ & $30 \%$ \\
\hline
\end{tabular}

En cuanto a los contaminantes, partículas de suciedad, microorganismos y gases que proceden del exterior o de la propia descomposición de los materiales, afectan sobre todo a la imagen, y deben ser reducidos al mínimo mediante una renovación del aire lo más constante posible. Alfonso del Amo (2006) indica que se puede llegar a ofrecer un buen espacio de conservación a los materiales fílmicos únicamente asegurando este cambio de aire constante.

Junto con las condiciones ambientales, hay que pensar en la protección directa de las películas y en el mobiliario más adecuado para el almacenamiento de las mismas. Existen para su elección recomendaciones ISO para cada material, por lo que seguimos recurriendo en los mismos textos de referencia. Se recomienda siempre que hayan pasado las pruebas de Photograhic Activity Test diseñadas por el IPI.

\section{PROPUESTA DE ADECUACIÓN DEL ESPACIO DE LA FILMOTECA DE PRÁCTICAS}

Una vez analizados los puntos anteriores, la conclusión clara es que el espacio que está actualmente utilizándose para la conservación de la colección está muy alejado de los ideales que propone la literatura para la conservación a largo plazo de material fílmico, y presenta muchos problemas para su adecuación.

Aun así, se proponen a continuación una serie de medidas para mejorar en lo posible las condiciones en que se encuentra la colección, y así alargar su esperanza de vida.

División por materiales y usos: La descripción del espacio y la colección nos hace ver que no va a ser posible una diferenciación entre materiales de uso frecuente y de

\footnotetext{
${ }^{7}$ ISO 18911 Imaging materials - Processed safety photographic films - Storage practices Geneva: International Organization for Standardization, 2000

${ }^{8}$ ISO 18911

${ }^{9}$ ISO 18923 Imaging materials - Polyester-base magnetic tape - Storage practices. Geneva: International Organization for Standarization, 2002
} 
conservación. Además, los espacios de trabajo y de almacenamiento van a ser compartidos. Por lo tanto, se considera que las condiciones del espacio de que se dispone deberán ir encaminadas a alcanzar los estándares de conservación a largo plazo. Por otro lado, a corto plazo no se prevé que haya un uso externo de las copias que alberga la colección, por lo que no habría que contemplar la conservación de uso frecuente fuera del entorno controlado de la Filmoteca de Prácticas.

Condiciones climáticas: La temperatura media que se ha estimado es de $20^{\circ} \mathrm{C}$ y la humedad relativa de 53\%. Según Adelstein (2004) nos encontraríamos en los parámetros que él ha definido como room conditions. Siguiendo con su tabla de sugerencias, estas condiciones van a producir daños significativos en los materiales fílmicos que están sometidos a ellas, tanto en las películas soporte acetato, como de color y los magnéticos. Se habla en el texto de una duración estimada de los materiales de unos 40 años, partiendo de materiales nuevos.

Para conseguir llegar a unas condiciones definidas en el texto como fair conditions, que no llegan a ser las propuestas por los estándares ISO pero van a prolongar la vida de nuestros materiales, tendríamos que bajar la temperatura unos $8^{\circ} \mathrm{C}$ durante todo el año y controlar que la humedad relativa no supere nunca el $50 \%$.

Como ya se ha comentado, el control de la temperatura va a ser complicado, puesto que el espacio está conectado con otro utilizado para una actividad totalmente diferente, y que precisa, en los meses de invierno, de calefacción.

Las acciones principales que se recomiendan son:

- Eliminar la conexión con el espacio inferior en la medida de lo posible.

- Eliminar el uso de los radiadores en la zona superior del espacio.

- Colocar el mobiliario lo más alejado posible de estas fuentes de calor.

- Realizar una abertura que permitiera la ventilación en la puerta de acceso y a ser posible en el lucernario, para que se produjera una corriente de aire.

- Mantener siempre algunas de las ventanas de la zona inferior abiertas para favorecer esta corriente de aire.

- Hacer uso de ventiladores durante periodos de tiempo programados a la semana para forzar este flujo de aire y ayudar a eliminar, sobre todo, los gases contaminantes emitidos por los materiales en descomposición.

Una vez aplicadas estas medidas, lo ideal sería monitorizar los cambios de temperatura durante un año en varios puntos del archivo, tanto dentro como fuera de las estanterías y armarios de almacenaje.

Mobiliario: El mobiliario del que se dispone ahora mismo se compone de:

- 1 Mesa de oficina con patas metálicas y sobre de madera.

- 1 armario metálico con puertas.

- 1 armario de madera con puertas.

- 1 estantería baja de madera.

- 1 estantería baja metálica.

El problema principal de este mobiliario no es la falta de uniformidad, sino la incapacidad de albergar por completo la colección de forma cómoda para su acceso. 
Las latas, como se puede ver en las imágenes adjuntas, tienen que colocarse incluso en la parte externa de los armarios de puertas, y en algunos puntos forman columnas de más de 15 latas.

Para que sea más efectiva la ventilación en el espacio de almacenamiento, se tendría que recurrir mejor a las estanterías abiertas, preferiblemente metálicas, puesto que estas permiten que la corriente de aire pase entre ellas con más facilidad. A esto habría que añadir la distribución de las estanterías, que estarían mejor dispuesta de forma trasversal a la pared del almacén, para facilitar el flujo en la mayor parte de ellas y eliminar el contacto con las paredes que pueden transferirle humedad y temperatura.

Protección directa de los materiales: lo ideal sería cambiar todos los envases por latas de conservación, que hayan pasado los estándares, pero esto supone una fuerte inversión. Por el momento, lo más urgente sería dotar de protección a las películas que no presentan ningún tipo. Esto quizás pueda hacerse mediante alguna donación de material por parte de algún otro archivo fílmico que pueda permitírselo.

El tipo de envase más adecuado para conservar estos materiales es el de plástico con ventilación, adecuando las medidas a las necesidades de cada rollo o bobina.

Equipamiento para el trabajo: el material de que dispone actualmente la Filmoteca de Prácticas es:

- Dos sincronizadoras de $16 \mathrm{~mm}$

- Una sincronizadora de $35 \mathrm{~mm}$

- Dos brazos bobinadores con pletina.

- Moviolas de Super 8 y $8 \mathrm{~mm}$

- Proyectores de $16 \mathrm{~mm}$, Super 8 y $8 \mathrm{~mm}$

Queda patente que hay que realizar una pequeña inversión en la Filmoteca de Prácticas para poder poner en marcha el trabajo con los estudiantes. Se recomienda completar la lista que recoge The Film Preservation Guide. La adquisición de este equipamiento puede ser difícil, sobre todo en el caso del más específico, pero se pueden plantear campañas de donación y colaboraciones con otros archivos fílmicos o instituciones que puedan compartir su material o facilitar el acceso al mismo.

\section{PROTOCOLOS DE ACTUACIÓN}

Este apartado se refiere a la definición de acciones que deberían de realizarse dentro de la Filmoteca de prácticas. Se trata de sugerencias o puntos de partida que podrían ser desarrollados posteriormente.

El primer paso es definir la forma de acceso de nuevos materiales a la colección. Para ello habrá que destinar un espacio específico dentro de las estanterías de almacenaje, puesto que el material recién adquirido necesita ser procesado antes de incorporarse permanentemente a la colección y ocupar un lugar definitivo dentro de las estanterías.

Lo más importante en estos casos es recabar cuanta más información mejor sobre el origen del material. Al formulario que se debe rellenar, se le adjuntará todo el mate- 
rial extra que se tenga o se encuentre. También es importante incluir información sobre dónde ha estado custodiado el material hasta el momento, las condiciones climáticas, y muy importante es determinar si puede estar infectado por hongos o bacterias, para que no contamine el resto de la colección. A continuación se le dará a la colección y a cada material un número de referencia que pasará a identificarlo dentro de la Filmoteca de Prácticas.

Teniendo en cuenta los materiales ya existentes en la colección, y basándonos en la forma de numerar en otros archivos fílmicos, se propone lo siguiente:

- Utilizar números correlativos por orden de llegada a la Filmoteca de Prácticas.

- Incorporar en la numeración el año para no utilizar números muy elevados y tener una visión rápida de la cantidad de adquisiciones anuales que se realizan.

- Utilizar para los materiales ya existentes en la Filmoteca de Prácticas la ordenación que seguían las pegatinas blancas de las latas. Algunas se han perdido, pero se puede establecer un orden hipotético.

- Utilizar la fecha de 2015 para los materiales ya existentes, puesto que es la fecha en la que se han incorporado a la recién creada Filmoteca de Prácticas.

- Podría plantearse realizar también una división por colecciones, puesto que tras el inventario inicial se pueden identificar varias.

El número final quedaría así: 2015:0001:0001 (año: colección: ítem)

El siguiente paso será procesar los materiales, es decir, realizar una inspección física para comprobar su estado de conservación y, siempre que sea posible, realizar una visualización del contenido para definirlo y realizar una catalogación más precisa.

Una vez se haya completado el procesado, se puede otorgar a cada lata un número de localización para ubicarlo dentro de la colección.

Se propone también una numeración topográfica. Como se ha comentado anteriormente, es preferible colocar los materiales en las estanterías ordenados por pasos y tamaño de latas, de esta forma se aprovecha mejor el espacio.

Sería ideal ordenarlos por tipo de elemento e incluso tipo de emulsión, en caso de que en un futuro se pueda acceder a un almacenaje con varias áreas de climatización.

Esta forma de organización se basa en la que utilizan grandes archivos fílmicos, que separan por elementos y por materiales, y más concretamente en la de George Eastman House.

La signatura topográfica descriptiva se conformaría por tres letras y cuatro números:

- Primera letra: identificaría el tipo de material (en nuestro caso actual, siempre acetato) y el tamaño de la lata. (35 mm - 600m: A; 35 mm - 1200 m: B; 16 mm - 360 m: C; etc.)

- Segunda letra: identificaría el tipo de elemento y el tipo de emulsión. (Positivo - B/N copia: G; Positivo - B/N solo imagen: H; Positivo - Color copia: I; etc.)

- Primer número: la estantería, empezando desde la más alejada a la puerta de entrada.

- Tercera letra: estante, ordenando siempre de abajo hacia arriba. 
- Cuarto número: posición dentro del estante, desde la pared hacia afuera.

- Quinto número: posición en la columna, de abajo hacia arriba.

De esta forma, en un solo vistazo, podemos saber qué tipo de elemento tenemos (copia de proyección), qué tipo de paso y la longitud aproximada.

Se han creado una serie de formularios especialmente diseñados para el uso en la Filmoteca de Prácticas que cumplen con la función de recoger la información necesaria para mantener la colección perfectamente identificada y ordenada. Este tipo de documentos es fundamental en cualquier archivo fílmico porque contempla toda la información que se puede obtener de un documento audiovisual, considerándolo desde todas sus perspectivas:

- El formulario de acceso recoge los datos sobre la proveniencia del objeto físico. Además, recoge la información legal sobre derechos de propiedad del objeto y el tipo de contrato que se establece con el propietario para sus posibles usos.

- El informe de inspección analiza la parte física del objeto, sus características formales y su estado de deterioro, que supone un dato muy importante a la hora de establecer prioridades de intervención

- El informe de visualización trata las cualidades del documento a la hora de su reproducción, la calidad con que la información contenida en el objeto físico va a llegar al usuario. Estos datos pueden identificar diferentes copias de una misma obra.

- El informe de catalogación, por último, recoge los datos filmográficos del documento, contenido intelectual y legal, y permite la identificación de la obra matriz, de la que luego podemos encontrar diferentes elementos.

Para su elaboración se han tomado como referencia los formularios de la Filmoteca Española, la Filmoteca Navarra, la George Eastman House, así como las sugerencias que se indican en los diversos manuales consultados.

\section{CONCLUSIONES}

La investigación que hemos llevado a cabo es el comienzo de lo que esperamos sea un avance para que futuros alumnos y usuarios puedan seguir llevando adelante y aprender con él. Se han ido trazando varios puntos y objetivos esenciales a lo largo de toda esta investigación que no deberían olvidarse en la creación de futuros trabajos, ya que se considera que queda aún mucha labor que hacer en este espacio.

El proyecto en el que se incluye este trabajo tendrá como objetivos principales la investigación, conservación y acceso a los materiales fílmicos que conforman su colección, y sobre todo, la formación práctica y el contacto de los alumnos con este tipo de documentos. No tenemos constancia de que exista en España ninguna otra Filmoteca de Prácticas, por lo que si se sigue desarrollando este proyecto adecuadamente puede convertirse en un referente. 
Para que este proyecto siga adelante se debería plantear la necesidad de tener a su cargo personas especializadas, que puedan enseñar a los usuarios un correcto funcionamiento del material para que puedan disfrutar y aprender. Estos especialistas deberían de encargarse también de gestionar correctamente el archivo en base a lo que en este trabajo se plantea. El trabajo realizado hasta el momento se resume en varios puntos:

- Importancia de llevar a cabo una labor más detallada de catalogación e investigación. La información recabada en este trabajo debe tomarse como una ayuda y un inicio.

- Aprender del proceso de investigación. Conocer su historia hace apreciar aún más el valor de esta colección.

- Necesidad de aplicar los conceptos que aquí se han sugerido y adaptar la colección a un espacio adaptado que pueda alargar su vida. Este trabajo debe servir de pauta para futuras vías de investigación y ayudar en el proceso de adaptación del fondo.

- Necesidad de colaborar con profesionales de otras instituciones que puedan aportar su conocimiento. La labor y el consejo de alguien profesional siempre puede ser de gran ayuda.

- Dar a conocer el espacio. Una vez se ponga en marcha debería plantearse el hecho de crear difusión de su existencia con la idea de conseguir el mayor apoyo posible. La importancia de una buena preservación del patrimonio fílmico pone en valor la labor llevada a cabo en esta investigación.

Entendiendo las limitaciones del espacio, mientras se busca una mejor localización para albergarlos se debe realizar una serie de acciones para mejorar las condiciones de almacenamiento del material fílmico:

- Mejorar la ventilación, ya sea de forma natural o artificial.

- Completar el mobiliario de almacenaje para poder colocar toda la colección de forma ordenada y segura.

- Dotar de protección individual a todos los materiales que carezcan de ella.

- Completar el equipamiento básico que propone The Film Preservation Guide para poder iniciar el trabajo con los materiales de la colección.

Este proyecto puede llegar a convertirse en un referente no sólo dentro de la comunidad universitaria, sino en la comunidad internacional de archivos fílmicos.

\section{REFERENCIAS BIBLIOGRÁFICAS}

ADELSTEIN, P.Z. (1993). IPI Storage guide for acetate film. Rochester: Image Permanence Institute.

ADELSTEIN, P.Z. (2004). IPI Media Storage quick reference. Rochester: Image Permanence Institute.

CATALINA, F., DEL AMO, Alfonso. (1999). Los soportes de la cinematografía 2. Madrid: Filmoteca Española. Cuadernos de la Filmoteca número 6. 
DEL AMO, Alfonso. (2006). Clasificar para preservar. México: Cineteca Nacional.

DEL AMO, Alfonso. (1996). Inspección técnica de materiales en el archivo de una filmoteca. Madrid: Filmoteca Española.

VALLE GASTAMINZA, Félix. Catalogación digital y metadatos audiovisuales. Jornadas Académicas sobre técnica y gestión en los archivos audiovisuales. 2014.

EDMONSON, Ray. (2004). Filosofía y Principios de los Archivos Audiovisuales. París: Unesco.

HARRISON, Harriet (1991) The FIAF cataloguing rules for film archives. Munich: K G Saur.

HIDALGO GOYANES, Paloma. Bases de Datos. La informatización de la información en los servicios de documentación. Jornadas Académicas sobre técnica y gestión en los archivos audiovisuales. 2014.

HIDALGO GOYANES, Paloma. La catalogación de los contenidos audiovisuales. Jornadas Académicas sobre técnica y gestión en los archivos audiovisuales. 2014.

ISO 18911 Imaging materials - Processed safety photographic films - Storage practices. Geneva: International Organization for Standardization, 2000.

ISO 18923 Imaging materials - Polyester-base magnetic tape - Storage practices. Geneva: International Organization for Standarization, 2002.

NFPF (2004). The Film Preservation Guide. The basics for archives, libraries and museums. San Francisco: National Film Preservation Foundation.

TORRES, R.A., APONTE, M R. (2010) Principios y técnicas en un archivo audiovisual. Bogotá: Fundación Patrimonio Fïlmico Colombiano.

VAL DEL OMAR, José. Dilema y Poder- Las técnicas de conquista psico-fisiológica y el respeto a la intimidad del espectador (1961)

VALLE GASTAMINZA, Félix (2014) Catalogación digital y metadatos audiovisuales. Jornadas Académicas sobre técnica y gestión en los archivos audiovisuales. Material inédito. Bogotá (Colombia)

\section{ANEXOS}

Disponibles en la versión electrónica de la revista. 